\title{
A narrativa brasileira no século XXl: Ferréz e a escrita do testemunho
}

\author{
The brazilian narrative in the 21 st century: Ferréz and the testimonial writing
}

\author{
Ana Paula Franco Nobile Brandileone \\ VANDERLÉIA DA SILVA OLIVEIRA \\ Universidade Estadual do Norte do Paraná/CCP - Jacarezinho - Paraná - Brasil
}

a

\begin{abstract}
Resumo: Apreciação crítica quanto à multiplicidade da narrativa brasileira no século XXI, com ênfase na escrita testemunhal de Ferréz no romance Capão pecado (2005), a fim de discutir certa tendência literária na qual os romancistas/contistas dedicam-se à defesa das causas e das experiências dos oprimidos, representadas em cenários de violência, por meio da escrita ficcional. Discute-se, pois, o modo como romances dessa natureza se relacionam com o contexto histórico atual e, consequentemente, como são recepcionados criticamente.
\end{abstract}

Palavras-chave: Narrativa contemporânea; Romance; Crítica literária

\begin{abstract}
Critical appraisal on the multiplicity of Brazilian narrative in the twentieth century, with emphasis on written testimonial of Ferréz in Capão pecado novel (2005), in order to discuss certain literary trend in which the male novel/short story writers are dedicated to defending the causes and the experiences of the oppressed ones, represented in scenarios of violence, by means of the fiction writing. It is discussed, then, the way novels of this nature are related with the current historical context and, consequently, as are critically received.
\end{abstract}

Keywords: Contemporary narrative; Novel; Literary Criticism

\section{Caminhos da Narrativa Brasileira Contemporânea}

No século XX o romance não apenas não morreu, contrariando os prognósticos de Lukács ( $\mathrm{s} / \mathrm{d}$ ), como se consolidou como gênero adequado para o estudo das representações humanas. Neste início do século XXI, o romance tem se desdobrado em subgêneros, em variadas linhas de força, alcançando uma dimensão significativa nas tendências contemporâneas, o que reforça seu caráter ambivalente e, ao mesmo tempo, inacabado.

Ao refletir sobre a pergunta "O romance está morrendo?", Fehér (1972) afirma que o gênero não é problemático, mas ambivalente, pois, segundo ele, o que se tem no desenvolvimento do romance é um enriquecimento desse gênero, que comporta uma diversidade cada vez maior de elementos produzidos por uma civilização, também cada vez mais complexa. A ambivalência geral do romance está no fato de que ele provém da sociedade burguesa e reage contra ela, o que leva não à morte do romance, mas sim à configuração de uma crise de representação (cf. FEHÉR, 1972, p. 25).
Interessante pensar nesta crise de representação diante de tamanha variedade de produção na literatura brasileira contemporânea. Aliás, mesmo os romancistas/ contistas tendem a discutir esta crise, indagando-se sobre o fim do escritor, do romance, enfim, da Literatura. Exemplo desta prática é o livro de crônicas $O$ romance morreu (2007), de Rubem Fonseca, no qual o autor apresenta um texto homônimo discutindo sobre o fim da literatura, da ficção e sugere que, na verdade, não são os escritores e seus textos que estão morrendo, mas sim os leitores de romance. Tal provocação instiga a pensar, portanto, na recepção da literatura contemporânea, diante de tantas mudanças no cenário da vida pós-moderna e, consequentemente, o quanto estas mudanças influem nos modos de representação e estratégias discursivas escolhidas pelo escritor e que, de certa maneira, mantém a literatura viva, por mais que se anunciem sua morte.

Assim sendo, analisar, definir e/ou sintetizar a narrativa brasileira contemporânea hoje é uma empreitada complexa que exige critérios para demarcar os limites espaciotemporais, o reconhecimento e o destrinchamento de variantes. Investir nessa reflexão quando se está 
dentro desses limites é temerário, mas, ao mesmo tempo, necessário. Temerário porque de um lado a proximidade temporal entre autor e leitor favorece a identificação e, portanto, uma análise parcial, o que pode levar a conclusões precipitadas - o risco é permanente. Por outro lado, a tentação de apreender a narrativa brasileira dos tempos atuais leva não só à tentativa de categorizar a produção literária, mas também à busca por nomes representativos de projetos estéticos e/ou práticas textuais. Como em toda escolha, a inclusão e a exclusão é uma consequência inevitável, daí grande parte dos críticos se mostrarem reticentes, evitando lançar prognósticos equivocados sobre a qualidade das obras, sobre autores que figurarão ou não no cânone e sobre a possível representatividade literária delas no circuito da crítica e historiografia literária brasileira, dada a multiplicidade de formas e temas das produções narrativas contemporâneas.

Termômetro dessa insegurança em apontar o que pode vir a ser consagrado ou não pela posteridade são as considerações de Helena Bonito Pereira e Lílian Lopondo que, na apresentação do livro Novas leituras da ficção brasileira no século XXI (2011), uma coletânea de 15 ensaios, declaram: "As narrativas que aqui se encontram analisadas já superaram um crivo anterior, tendo sido premiadas ou pelo menos indicadas em listas de concursos nacionais ou internacionais [...]" (PEREIRA; LOPONDO, 2011, p. 17). O que se pode inferir dessas palavras é que ao considerarem as premiações ou indicações em concursos como pré-requisitos para a seleção das narrativas estão tentando se "livrar" dos possíveis questionamentos e avaliações: Por que estes e não outros? Que critérios nortearam a escolhas desses autores e obras? Por que estes critérios e não outros?

Outro exemplo desse esvaziamento da crítica literária no que ela tem de mais basilar, que é o exercício da avaliação e do julgamento, é Ítalo Moriconi que, em ensaio intitulado "A literatura ainda vale?" (2002), afirma que por conta dos variados temas e múltiplos procedimentos narrativos o adjetivo "contemporânea" funciona como um termo vazio a ser preenchido a posteriori pela crítica e pela história literária. Com o quê parece discordar Paulo César Silva de Oliveira (2013) quando afirma:

Apesar de tudo, é preciso estudar literatura contemporânea, a qual se mostra efervescente e instigante a despeito do que pensa a academia. Desta forma, esta pesquisa não pode temer o risco do agir, em que qualquer decisão implica escolha e exclusão; não esquecimento, mas sim preferência por certos autores, temáticas, formas de narrar que, em última instância, revelam um problema na teoria atual, que finge não ver: o papel do crítico, que se esconde e/ou manifesta por detrás dos textos e autores que elege.
Ou seja, o intelectual que fala através/do texto, em dado momento precisa se manifestar, dizer presente, mesmo que advogue uma suposta 'neutralidade' face às opções que faz. (OLIVEIRA, 2013)

Por isso, a atitude inversa, isto é, a recusa do crítico literário em elaborar qualquer tipo de síntese também incorre em risco: de um lado porque a isenção não é o melhor caminho para minimizar as incoerências que surgirão no percurso crítico; ser interrogado nas escolhas que faz é sinal de que o debate está aberto, que o objeto que interroga sempre inaugura novas leituras e que, fundamentalmente, todo ponto de vista, todo critério, toda categorização é relativa, ou seja, não está imune ao tempo. Por outro lado, porque a ausência e/ou a forma de discurso anódino que evita o confronto, bem como "foge" de um posicionamento claro diante da cultura e da literatura contemporâneas pode estar a serviço de outros interesses. Para Paulo Franchetti (2012), o que se assiste hoje na vida literária brasileira é a "demissão da crítica" que, por sua vez, está ligada, dentre outros fatores, às necessidades de se ajustar aos imperativos da indústria e do comércio, jornalístico e livreiro.

Alguns, no entanto, como Beatriz Resende (2008), arriscam-se em tecer análises sobre estas produções e autores, na tentativa de definir, ainda que provisoriamente, traços e marcas desta época. Para a autora, a proliferação de novos nomes e obras é de tal forma vasta e múltipla que não é possível a apreensão de todo o seu universo, por isso limita-se a por em destaque algumas dominantes presentes na ficção atual.

A fertilidade e multiplicidade dessa produção literária também não passaram despercebidas por Helena Bonito Pereira e Lílian Lopondo: "Um olhar de relance aos escritores revela de imediato a diversidade, em termos de faixa etária, ano de estreia, volume ou regularidade de suas publicações, importância ou reconhecimento acadêmico e crítico" (PEREIRA; LOPONDO, 2011, p. 19). As autoras lembram a coexistência de autores já reconhecidos no panorama da literatura brasileira como Nélida Piñon, Moacyr Scliar e Modesto Carone, estreantes no final da década de 1960 e década de 1970, respectivamente, ao lado de autores recém-chegados, como Daniel Galera, Maria Esther Maciel, Mário Sabino e Ruy Câmara, com livros lançados em 2003, dentre tantos outros (cf. PEREIRA; LOPONDO, 2011, p. 19-20).

Resende evidencia que essa heterogeneidade - traço diferenciador neste novo momento da literatura brasileira - revela-se ainda na linguagem, nos formatos, no suporte, nos diversos tons e temas por isso para melhor compreendê-la é necessário "deslocar a atenção de modelos, conceitos e espaços que nos eram familiares até tempos atrás" (RESENDE, 2008, p.15), porque "múltiplas 
convicções sobre o que é literatura" (RESENDE, 2008, p. 18).

Esta última citação encontra ressonância nas considerações de Antonio Candido, em "A nova narrativa", uma vez que o autor assinala a predileção dessa literatura pelos híbridos e pela reversibilidade entre os diferentes registros escritos, das quais resulta o diálogo constante com a imagem e com registros não literários, bem como a dissolução, muitas vezes, das fronteiras entre ficção e não ficção.

Para Karl Eric Schøllhammer - outro crítico que se propõe a desenhar alguns aspectos da narrativa brasileira contemporânea -, essa nova forma de expressão se dá por conta dos autores desejarem "provocar efeitos de realidade por outros meios" $(2011$, p. 54$)$, que vão desde a sua integração com o mercado e com os meios de comunicação de grande alcance, como a televisão e o cinema, aos mais diversos recursos estilísticos e técnicas narrativas.

Não é incomum encontrar alguns críticos ou mesmo escritores que acusam a narrativa contemporânea de exibir um excesso de realismo, igualando-se à mídia, cujo interesse se centra na "vida real", na "vida como ela é". É o caso de Schøllhammer, que considera a literatura hoje não muito diferente nem melhor na relação que estabelece com os meios de comunicação, na sua sede de nos superexpor à realidade, já que "[...] o que mais vende são biografias e reportagens históricas, confissões, diários, cartas, relatos de viagens, memórias, revelações de paparazzi, autobiografias e, claro, autoajuda" (SCHØLLHAMMER, 2011, p.56). Por isso mesmo, diz o estudioso, que as artes e a literatura têm como desafio encontrar outra expressão de realidade que "por um lado, [deve] se desvencilhar da proliferação mimética visível nas coberturas presencias da mídia e, por outro, deve se diferenciar do uso das técnicas de choque e do escândalo, já muito instrumentalizadas pela indústria midiática e pelas vanguardas modernistas" (SCHØLLHAMMER, 2011, p. 57-58).

Essa sede de realidade significa para alguns, como João Silvério Trevisan, o retorno à premissa da tradição realista. Segundo o escritor, em palestra intitulada "O estandarte rubro da poesia", proferida no XI SEL (Seminário de Estudos Literários), realizado entre 24 a 26 de outubro de 2012, na UNESP, campus de Assis, há uma regressão ao realismo oitocentista, que se impõe por motivos extraliterários, bem como por oferecer a primazia do enredo em detrimento da expressão, ou como diz Leyla Perrone-Moisés (1998), privilegiando o o que da obra literária e esquecendo o como, aquilo em que se distingue e que é só seu, passando ao largo, nos dias atuais, do seu fundamento estético, dada a sua dimensão prioritariamente utilitária. Para Trevisan, essa ficção que se quer colada à realidade brasileira se move em favor dos parâmetros mercadológicos, uma vez que entrega ao leitor - antecipadamente determinado - uma fórmula digestiva, facilmente consumível: "o que se exalta é: quanto mais fácil de ler, melhor".

Ao contrário de Trevisan, Karl Eric (2011) encara o realismo da nova geração como uma negação aos realistas do passado, pois inexistem as técnicas da verossimilhança descritiva e da objetividade narrativa, ou seja, é um realismo que não pretende ser mimético nem propriamente representativo - posicionamento que não deixa de ser conflitante, como o próprio estudioso observa. Para o crítico, o que há por detrás da proposta dessa nova geração de escritores é a reinvenção desse realismo oitocentista, a partir da conciliação de duas vertentes da história literária brasileira: a vertente modernista e experimental e a vertente realista e engajada. Dentre os escritores que conjugam os temas da realidade social brasileira ao compromisso com a inovação das formas de expressão e das técnicas de escrita estão, segundo Schøllhammer (2011), Luiz Ruffato, Nelson de Oliveira, Bruno Zeni, Marçal de Aquino, Marcelino Freire, Joca Reiners Terron, Amilcar Bettega Barbosa, Ronaldo Bressane e Cláudio Galperin. Abaixo o que o crítico entende como esse "outro" tipo de realismo:

[...] reinventar as formas históricas do realismo literário numa literatura que lida com os problemas do país e que expõe as questões mais vulneráveis do crime, da violência, da corrupção e da miséria. Aqui, os efeitos de 'presença' se aliam a um sentido específico de experiência, uma eficiência estética buscada numa linguagem e num estilo mais enfáticos e nos efeitos contundentes de diversas técnicas não representativas de apropriação dessa realidade. $\mathrm{O}$ uso das formas breves, a adaptação de uma linguagem curta e fragmentária e o namoro com a crônica são algumas expressões da urgência de falar sobre e com o 'real'. (SCHØLLHAMMER, 2011, p. 14-15).

Os traços acima apresentados têm sido frequentemente apontados como sendo as principais marcas da narrativa contemporânea, não por acaso (re)aparece em alguns estudos que se centram em indicar algumas dominantes dessa produção literária. A fragmentação da narrativa é aspecto apontado por Helena Bonito Pereira (2011), o qual, por sua vez, mostra-se como efeito da invasão tecnológica e da contaminação das outras mídias, e se manifesta na linguagem narrativa pelos vazios na página escrita, por cortes abruptos no tempo e espaço diegéticos, bem como por múltiplos planos temporais e espaciais que se interpenetram, comprometendo a coerência e contribuindo para a instauração do caos que, não raro, se associa às personagens, cada vez mais proble- 
máticas; anti-heróis em permanente dissonância com o mundo.

A presença dos contos curtos e/ou outras formas mínimas de escrita ${ }^{1}$ é outra faceta da literatura contemporânea que, pelo caráter de flagrante ou de instantaneidade, pode ser entendido como uma radicalização da crônica e cujo impacto da experiência direta atinge em cheio o leitor, dado o efeito contundente da realidade exposta. Essa tendência da literatura nos dias atuais traduz, na verdade, a intenção de captar o leitor contemporâneo e as demandas do seu tempo, que vive igualmente a dinâmica da urgência e do imediato e, por isso, o pendor ao rapidamente lido; textos, como bem afirma Beatriz Resende, "para serem lidos de um só fôlego" (RESENDE, 2008, p. 28).

Outra característica dessa ficção contemporânea e apontada como uma das suas mais significativas linhas de força é a presença da violência, que aparece nas suas mais diferentes formas: alienação, preconceito (minorias social, étnica, sexual), discriminação, intolerância, exclusão, segregação, autoritarismo, criminalidade (seja sob as formas de assassinatos, latrocínios, assaltos, sequestros, vandalismo, estupro, ou pedofilia), violência linguística, moral, silenciamento etc. Para Resende, a questão da violência aparece na "urgência da presentificação e da dominância do trágico, em angústia recorrente, com a inserção do autor contemporâneo na grande cidade, na metrópole imersa numa realidade temporal de trocas tão globais quanto barbaramente desiguais" (RESENDE, 2008, p. 33).

Vale destacar, entretanto, que essa relação entre literatura e violência social e/ou literatura e marginalidade já esteve presente na narrativa da década de 1930, não sendo, por assim dizer, exclusividade da atual narrativa brasileira, que a perpetua em tons realistas, segundo Antonio Candido, em “A nova narrativa" (1987). Também a pretensão de criticar o desequilíbrio social, não raro pelo olhar do marginalizado, volta a aparecer nas narrativas contemporâneas, mas agora ganhando contornos de inovação, sob uma vertente mais brutalista, que o crítico denomina de "realismo feroz" ou "ultrarrealismo". Para Candido, nessa vertente ultrarrealista o escritor agride o leitor não apenas pelos temas que escolhe, mas também pelos recursos técnicos que emprega: "O que vale é o Impacto, produzido pela Habilidade ou pela Força. Não se deseja emocionar nem suscitar contemplação, mas causar choque no leitor [...], por meio de textos que penetram

\footnotetext{
É o caso da obra de João Gilberto Noll, Mínimos, múltiplos, comuns, publicada em 2004, num volume que compila os 338 textos publicados no jornal Folha de São Paulo, durante 3 anos e 4 meses; narrativas de no máximo 130 palavras. Também Marcelino Freire, em iniciativa pioneira, propôs a uma série de autores que escrevessem contos de até 50 palavras, o que deu origem ao livro Os cem menores contos brasileiros do século, de 2004.
}

com vigor mas não se deixam avaliar com facilidade" (CANDIDO, 1987, p. 214).

Associada à tematização da violência inscreve-se a representação da realidade marginal e periférica que, por sua vez, coloca o leitor no rumo de uma espécie de notícia crua da vida brasileira. Esta discussão está intrinsecamente ligada ao interesse em trazer para o centro a massa dos excluídos sociais - grupos históricos e socialmente desfavorecidos e, por isso, silenciados - e, assim, tratar da desigualdade social e econômica, da criminalidade, das injustiças, da miséria e da violência policial, bem como dos espaços não valorizados socialmente: a periferia dos grandes centros urbanos ou os enclaves murados em seu interior, como as prisões (destaque para os romances Cidade de Deus e Carandiru). Relevante dizer que nesse contexto não basta dar voz aos grupos excluídos da sociedade e/ou da história "oficial” por vozes que buscam falar em nome deles; o que importa é o olhar de dentro, do próprio excluído, de onde deve emergir a denúncia, o protesto, tornando-o assim agente da sua própria história.

Se o espaço do sertãoé que deu o tom nas representações da violência em muitos romances da história da literatura brasileira, como Os Sertões, de Euclides da Cunha, que conta a história da Guerra de Canudos, disputa entre republicanos que queriam "civilizar" e os representantes da "velha ordem", os monarquistas, ou então Vidas Secas, de Graciliano Ramos, e Grande sertão: veredas, de Guimarães Rosa, cuja violência se instala pelo confronto entre um sistema global de justiça moderno e sistemas locais de normatização social regulado pelos códigos de honra, vingança e retaliação, na literatura contemporânea o espaço urbano, especialmente o das grandes cidades, é que se constitui como cenário privilegiado, e de onde emerge a diversidade sociocultural e, consequentemente, de onde se acenam recorrentes disputas e conflitos.

É então na força desse cotidiano urbano, nessa violência na e da cidade, que se inscreve um mal-estar que não é circunstancial, mas existencial, porque ligado a crises e conflitos vividos por sujeitos sociais cindidos, despedaçados, desenraizados, marginalizados, excluídos, abandonados à deriva, expostos a uma sem ordens de violência e/ou a uma vida cotidiana burocrática e impessoal. Por isso, os contornos dos seres e das coisas, não raro, também adquirem dimensões irreais, pois a tentativa de configurar os sinais da cidade e de seus "habitantes-personagens" leva o romancista a adentrar no reino do fragmentário e/ou do absurdo, a fim de compor a falta de sentido da vida contemporânea.

São muitas as tendências na abordagem da violência urbana na nossa produção ficcional atual, muitos os recursos estéticos mobilizados para (re)apresentar e/ ou (re)simbolizar o fenômeno da violência na dinâmica cultural contemporânea. Nesse sentido, a violência pode 
manifestar-se no plano da linguagem e das representações, como evidência de dissidência ou da iminência de uma situação de caos social; ou então como expressão de novas expressões do social, cada vez menos passível a avaliações reguladoras e/ou moralizantes; ou ainda como enunciação genuína e, às vezes, legítima de conflitos vivenciados no dia-a-dia da vida social. Pode ainda, para alguns escritores, assumir um papel especial: que é o da literatura dedicar-se à defesa das causas e das experiências dos oprimidos, como é o caso de Ferréz, que cria uma escritura de testemunho, sendo sujeito ele mesmo da realidade sobre a qual o escreve e, portanto, na qual interferem imperativos éticos.

\section{Capão Pecado: romance de testemunho}

A narrativa de Ferréz, pseudônimo de Reginaldo Ferreira da Silva, pode exemplificar uma faceta da ficção brasileira contemporânea, em especial a do gênero romance. Sua escrita tem a pretensão de tornar visível a voz periférica, por meio de uma estratégia narrativa na qual o próprio excluído narra a sua história e a do seu povo. Neste sentido, o cenário é o da periferia e o contexto narrativo o do cotidiano de seus moradores.

Tais aspectos propiciam uma discussão sobre o gênero romance, literariedade, autenticidade, narrativa de testemunho, dentre outros aspectos, tendo em vista a proximidade entre o escritor, morador da periferia, e seus narradores; além, é claro, das indagações sobre engajamento político, posicionamento crítico social e, também, sobre certas dinâmicas do mercado editorial.

Ferréz é autor de três romances: Capão Pecado, publicado em 2000, pela Labortexto Editorial, com uma segunda edição reformulada em 2005, pela Objetiva; Manual prático do ódio, de 2003, pela mesma editora, e Deus foi Almoçar, 2012, pela editora Planeta. Seu primeiro livro é de poesia concreta, de 1997, Fortaleza da Desilusão, patrocinado por uma empresa na qual o autor trabalhava. Publicou um livro de contos Ninguém é inocente em São Paulo, em 2006, pela Objetiva. Dois livros infantis: Amanhecer Esmeralda, de 2005, Objetiva, e $O$ pote mágico, pela Planeta, em 2012. Histórias em quadrinhos: Os inimigos não levam flores, pela Pixel Media, em 2006, e, em 2012, HQ Desterro, pela Anadarco Editora, ambos em parceria com o quadrinista Alexandre de Mayo. Também publicou crônicas: Cronista de um tempo ruim, 2009, primeiro de uma série do selo Povo, criado pelo próprio autor, reunindo textos publicados na revista Caros Amigos, no jornal Folha de S. Paulo, Le Monde Diplomatique Brasil, revista Trip, e Relatório da ONU. Organizou ainda a coletânea Literatura marginal: talentos da escrita periférica, pela Agir, em 2005. Foi colaborador da revista Caros Amigos durante 10 anos e, atualmente, escreve para a Revista Fórum. Escreveu roteiros para o filme Brother e os seriados Cidade dos Homens (02) e 9MM (Fox). Lançou, em 2009, o DVD Literatura e Resistência, com um documentário sobre sua trajetória. Fundou em 1999 a 1DASUL, marca de roupas produzidas no bairro Capão Redondo/SP e, em 2009, criou a ONG Interferência.

Como se vê, o escritor tem grande atuação junto à sua comunidade, desenvolvendo projetos e disseminando a voz da periferia. Pode-se dizer que Ferréz construiu uma identidade a partir da palavra escrita, inserindo-se no circuito cultural e editorial, seja pelas publicações ou pela participação em eventos culturais, literários, debatendo sobre literatura e outros temas, tanto no Brasil quanto no exterior. Certamente, tal atuação e produção exigem da crítica acadêmica um olhar inquisidor, já que certas balizas da tradição literária, em seus critérios avaliativos, têm sido reavaliadas. Formas de expressão, suportes, hibridismo de gêneros, temas, estatuto literário, dentre outras, são questões que pairam nas discussões acadêmicas quando produções como as de Ferréz se tornam objeto de investigação. Afinal, são narrativas Literárias? Sociológicas? Jornalísticas? Mercadológicas?

É evidente que, pelo conjunto de sua produção, Ferréz, escritor e embaixador da periferia, possui o chamado "olhar de dentro" mencionado por Resende (2008) em seus estudos. A partir deste aspecto nota-se, no mínimo, uma perspectiva problemática em sua narrativa, pois há a mistura entre as entidades: escritor e narrador. É o que evidencia, algumas vezes, a literatura escrita por mulheres, por negros e por periféricos, que possuem como "motivos da escrita" a própria condição humana, a de mulher, a de negro e a de estar à margem.

Se considerarmos o que Resende (2008) aponta sobre a produção contemporânea se desenvolver por meio de temas e formas múltiplas, uma consequência seria a de um duplo movimento de escritores: de um lado há os tradicionalistas que reconhecem na arte uma única função, que é a de obter um efeito pelo próprio narrado, por isso focam não "no" que se diz, mas em "como" se diz; de outro, os escritores que permitem à literatura outras funções, como a de revelar certa perspectiva social e política de modo mais engajado. Pode-se dizer que Ferréz se liga à segunda opção, pois revela uma escrita focada nas temáticas da margem, preocupada com questões sociais.

O romance Capão Pecado pode exemplificar muito bem o quanto a ficção contemporânea tem sido produzida por temas, formas e com estilos diversos. Publicada em 2000 a obra lançou o autor no mercado revelando o uso de um teor testemunhal, de uma intenção clara de representar seus iguais por meio da ficção. Sob este aspecto, a posição do autor é evidente: pela escrita literária dar voz aos 
moradores da periferia, representando certa "cor local" no texto que, em síntese, expressaria a realidade absoluta do cotidiano das pessoas que viviam no bairro Capão Redondo. O excesso de realismo, da representação da vida real, como entende Schøllhammer (2011) provocariam, portanto, efeitos de realidade ao leitor.

Para que a obra então provocasse esse efeito de realidade que, em certa medida, expressasse um interesse coletivo da e pela periferia, a edição contou com alguns suportes de estratégia de mercado, tais como a capa, na qual figurava a foto de um menino tendo a favela como fundo, fotos e textos de rap de grupos musicais, isto é, vozes de pessoas reais da periferia abrindo cada capítulo. Já na edição de 2005, pela editora Objetiva, outra estratégia de mercado é utilizada, uma vez que o autor já havia alcançado certa representação no espaço cultural: a capa vem mais "limpa", apenas com o nome do autor destacando-se sobre o título em tamanho menor, com fundo preto; desaparecem as fotos da favela e do autor, bem como os textos de rap; também uma nota do autor registra o processo de escrita do romance, além da inversão do prefácio para posfácio. Na edição anterior, Mano Brown, do grupo Racionais MC's, assinava o texto que abria a primeira parte, na de 2005, o texto é deslocado para a orelha. Tudo isso colabora para uma edição mais "limpa" que, de certo modo, legitima a "voz de um escritor" e não apenas a "voz de um morador da periferia que deseja ser escritor", como na primeira edição.

Da dedicatória geral da edição de 2000 para a de 2005 fica apenas a sintética dedicatória ao amigo falecido (como registro das tragédias que atingem os moradores da periferia) e a clara crítica ao sistema, demonstrada por meio da interlocução com o leitor pela epígrafe que abre a primeira parte do romance: "Querido Sistema, você pode até não ler, mas tudo bem, pelo menos viu a capa" (FERRÉZ, 2005, p. 11). Nesse sentido, pode-se dizer que importa para o autor a garantia mínima de um espaço intelectual, que é o da publicação de uma obra que, em grande medida, representa a marcação de um espaço de existência.

Aqui, optamos pela apresentação do romance em sua segunda edição. Nela, o texto se divide em vinte e três capítulos, distribuídos em cinco partes. Quatro delas antecedidas por textos de rap marcando a voz de companheiros - Ratão, Outraversão, Negredo, Garrett -, os quais tratam dos mesmos assuntos dos capítulos: violência, marginalização e desencontros marcados pelo cotidiano da periferia. Evidente que esta estratégia discursiva do uso da voz real de moradores da periferia e da voz do próprio escritor que lá reside, misturando-se à voz ficcional - que narrará em terceira pessoa a história de Rael, morador do bairro Capão Pecado, alusão à Capão Redondo, distrito periférico de São Paulo - estabelece um diálogo entre ficção e testemunho. Operam, ainda, um caráter de hibridismo entre textos referenciais e o discurso ficcional da narrativa.

No posfácio, o espaço narrativo é caracterizado por Ferréz como um local "por Deus abandonado e pelo diabo batizado [...]" (2005, p. 149). É nele que se instaura a narrativa, a partir da qual o autor ficcionaliza a sua própria vivência e a de seus companheiros. O narrador, para reforçar o pacto de verossimilhança, faz uso de uma linguagem popular e real, por meio da qual os elementos extraliterários determinarão a condução do narrado. Assim, reconhece-se no romance o caráter testemunhal de Ferréz que multiplica as vozes do texto revelando uma grande "voz coletiva". Este aspecto, inclusive, poderia nos remeter à ideia de que o romance, como gênero que se presta à representação do destino individual, em Ferréz acaba por trazer à tona uma representação coletiva ao tratar não do destino de um herói, mas sim de toda uma comunidade, a exemplo das epopeias. Certamente esta questão demandaria outra análise, o que não é o foco neste estudo, porém evidencia o quanto este tipo de narrativa pode desestabilizar certos modelos e evocar novos olhares, como afirma Resende (2008).

Com efeito, para intensificar a voz da periferia, a linguagem é fundamental na narrativa. Os exemplos abaixo demonstram o quanto a violência e a marginalidade são descritos como componentes intrínsecos no cotidiano do bairro:

A 2 metros dali seu amigo Testa sentia o frio do aço, quando este penetrou em sua boca $[. .$.$] os dentes foram$ arrancados pelo cano do revólver [...] Ele se entregou e aceitou a morte [...] são dois os tiros, e então três, mas o frio impedia o seu raciocínio e ele viu um médico, sua mãe o pegou no colo e beijou sua testa, seu pai lhe deu um caminhão no Natal [...] Mixaria lhe vendeu o primeiro cano, foi uma pistola GP-35 Browinng [...] foi também Mixaria que o convidou a cometer o seu primeiro assalto [...]. (FERRÉZ, 2005, p. 85-86)

[...] Rael não estava a fim de ouvir aquela conversa, mas sabia que não tinha como fugir do amigo de trabalho e resolveu perguntar:

- Catamos? Com quantos ela foi ontem?

- Vixe, ladrão! Ela foi comigo, com o Pássaro e com o Amarelos.

- Nossa, que piranha, mano! E ela rendeu pra todo mundo assim na maior?

- Que nada, mano. Eu catei primeiro e ela deixou eu dar uma colocada, mas não deu nem chance de eu tentar gozar, tá ligado? Ela tem mó medo, eu até tentei chavecar, mas ela teve que batê uma pra mim, pra completar o serviço. (FERRÉZ, 2005, p. 71)

A primeira citação trata de uma cena que traz uma retrospectiva da vida de um garoto que se envolveu nas 
drogas e acabou sendo morto pelo tráfico. Observa-se que a narração é colada ao referencial, o que faz com que a ficcionalidade se anule. A segunda inserida num diálogo maior entre Rael e seu colega de trabalho, também evidencia, além da linguagem coloquial, a carga sexual presente na narrativa, que se evidencia em muitas outras cenas, apresentando o sexo, na maioria delas, como uma força primitiva e de dominação.

Deste modo, o excesso do real, que para Schøllhammer (2011) é traço vinculado aos efeitos da realidade mimética, implica e uma narrativa que se constrói pela referencialidade imediata. Ao narrar a história de Rael (real) que possuía o sonho de se tornar escritor (como Ferréz?), Capão Pecado (2005) se configura como um eco da favela, uma voz que pode ser ouvida com o seu próprio discurso, não mais ocultado pelo discurso hegemônico do dominante. Ferréz, assim, torna-se agente de uma produção que recusa mediadores tradicionais e garante sua participação social. Aliás, de autor que teve sua primeira publicação financiada por seu empregador, Ferréz é hoje exemplo de como funcionam certos mecanismos de produção e recepção de bens simbólicos. Afinal, conquistou espaço cultural e político, assumindo uma postura de quase missão pedagógica pela escrita literária e construiu uma imagem de audácia, sucesso e de boa articulação com o mercado, como porta voz autêntico no debate sobre alguns dos complexos mecanismos excludentes da sociedade capitalista.

Evidentemente, o modo como o autor utiliza a escrita leva ao questionamento sobre certos conceitos do que é estética e composição narrativa, pelo excessivo uso de certo verismo etnográfico. Para Resende, por exemplo,

Quando esse realismo ocupa de forma tão radical a literatura, excesso de realidade pode se tornar banal, perder o impacto, começar a produzir indiferença em vez de impacto. O foco excessivamente fechado do mundo do crime termina por recortá-lo do espaço social e político, da vida pública. Torna-se então, ação passada em uma espécie de espaço neutro que não tem mais nada a ver com o leitor. Corre o risco de resultarem disso tudo, o mais das vezes, obras literárias que temo considerar descartáveis. (RESENDE, 2008, p. 38)

Eis aí o principal nó a desatar quando aplicamos certos conceitos de análise literária aos textos do autor. Afinal, o que se verifica é que a obra de Ferréz, devido a esse alto teor de realidade, deixa-se cair no utilitário e perde o aspecto literário, pois no enredo do livro Capão Pecado, pode-se notar uma representação literária engajada, focado na demonstração de uma realidade cruel da favela, onde os desfavorecidos trabalham para o capital do outro, e que pela falta de perspectiva social, o meio acaba por determinar, muitas vezes, o desfecho da vida dessas pessoas, causando os vícios da bebida e das drogas, como, também, impulsionando-os a atos violentos.

A falta de estranhamento, de lacunas a serem preenchidas pelo leitor, por exemplo, provém da ausência do uso de recursos narrativos que possam conferir ao texto ambiguidade, uma vez que o autor trabalha com a obviedade dos fatos e demonstra necessidade de justificar demasiadamente certas questões da narrativa em que tudo é explicado pelo meio influenciador, o que acaba tornando-a previsível, isenta de efeito literário. Ferréz determina o seu foco: confirmando um novo discurso, não mais o do "pobre preguiçoso", mas sim o do sujeito sem perspectiva e direitos iguais, somado às condições de vida injustas, gera um texto no qual o extraliterário se sobrepõe ao estético. A propósito, podemos perceber que esse tipo de escrita literária mesmo se constituindo próxima ao utilitarismo, é o que este escritor designa como a função de sua arte. O que não deixa de fazer-se válida, pois, como afirma Lins (1990), a Literatura também pode ser a transformadora de consciência, após a constante afirmação de um mesmo discurso no sistema literário.

A partir do exposto, pode-se dizer que Ferréz se apropria da esfera literária e utiliza a ficcionalização como pretexto para refletir valores ideológicos e sociais vigentes em nosso século, subvertendo assim o circuito literário, visto que, até então, a esfera marginal era narrada pela cultura majoritária. Esta escrita, portanto, exige da crítica literária uma nova percepção sobre a forma de elaboração do texto, dando a ela a oportunidade de reavaliar, também, seus modos de recepção diante destas novas dicções. Sob este aspecto, perguntas como Qual o sentido desta produção? O romance, como gênero, sucumbiu ao mercado? De que mercado falamos? Romances de testemunho tendem a dissolver a autoria, face aos interesses coletivos de representação? estão a exigir, no mínimo, reavaliação da crítica quanto aos seus próprios procedimentos de recepção no contexto mercadológico atual.

\section{Referências}

CANDIDO, Antonio. A nova narrativa. In: A educação pela noite e outros ensaios. São Paulo: Ática, 1987. p. 199-215.

FEHÉR, Ferenc. O romance está morrendo? Tradução Eduardo Lima. Rio de Janeiro: Paz e Terra, 1972.

FERRÉZ. Capão pecado. Rio de Janeiro: Objetiva, 2005.

FERRÉZ. Capão pecado. São Paulo: Labortexto Editorial, 2000.

FONSECA, R. O romance morreu. São Paulo: Cia. das Letras, 2007.

FRANCHETTI, Paulo. A demissão da crítica. Disponível em: $<$ http://www.germinaliteratura.com.br/enc_pfranchetti_abr5. htm>. Acesso em: 10 out. 2012.

HEGEL, Georg Wilhelm Friedric. Fenomenologia do espírito. Petrópolis: Vozes, 1992. 
LINS, Ronaldo Lima. Violencia e literatura. Rio de Janeiro: Tempo Brasileiro, 1990.

LUKÁCS, G. A teoria do romance. Tradução A. Margarido. Lisboa: Editorial Presença, s/d.

MORICONI, Ítalo. A literatura ainda vale? (literatura e prosa ficcional brasileira: estados da arte - notas de trabalho). In: CONGRESSO INTERNACIONAL DA ABRALIC, 8., 2002, Belo Horizonte. Anais... Belo Horizonte: UFMG, 2002.

OLIVEIRA, Paulo César Silva de. Inclusão, exclusão e as novas vozes do cânone ficcional brasileiro contemporâneo. In: CONGRESSO DE LEITURA DO BRASIL, 14., 2003, Campinas, SP. Anais... Campinas: UNICAMP, 2003.

PEREIRA, Helena Bonito. Breves apontamentos para a história literária brasileira. In: PEREIRA, Helena Bonito. Novas leituras da ficção brasileira no século XXI. São Paulo: Universidade Presbiteriana Mackenzie, 2011. p.31-49.
PEREIRA, Helena Bonito; LOPONDO, Lílian. Introdução. In: PEREIRA, Helena Bonito (Org.). Novas leituras da ficção brasileira no século XXI. São Paulo: Universidade Presbiteriana Mackenzie, 2011. p. 17-30.

PERRONE-MOISÉS, Leyla. Altas literaturas. São Paulo: Companhia das Letras, 1998.

RESENDE, Beatriz. Contemporâneos: Expressões da Literatura Brasileira no século XXI. Rio de Janeiro: Casa da Palavra/ Fundação Biblioteca Nacional, 2008. 175 p.

SCHØLLHAMMER, Karl Erik. Ficção brasileira contemporânea. 2. ed. Rio de Janeiro: Civilização Brasileira, 2011.

Recebido: 01 de julho de 2013 Aprovado: 22 de novembro de 2013 Contato: vances@uenp.edu.br apnobile@uenp.edu.br 